\title{
Comparative Analysis of Hemoglobin Content in Four Species of Anurans from the Ural Uplands
}

\author{
V. L. Vershinin ${ }^{a, b}$ and S. D. Vershinina ${ }^{a}$ \\ Presented by Academician D.S. Pavlov August 28, 2012
}

Received August 28, 2012

DOI: $10.1134 / \mathrm{S} 0012496613030137$

A change in the hemoglobin oxygen-binding capacities towards its maximal oxygen saturation (at its low content) was the strategy of the evolution of the blood respiratory function in Amphibia [1]. Therefore, Amphibia require a small oxygen partial pressure in the environment for the complete hemoglobin saturation with oxygen [2]. Since the respiratory function is performed in adult Amphibia by a whole set of organs, including the skin, lungs, and mucous membrane of the oropharyngeal cavity (as opposed to other terrestrial vertebrates), 50-90\% of oxygen comes in through them. The relative roles of different organs in respiration depend on the ecological specifics of the species. In the blood of Amphibia, hemoglobin plays the role of the original depositary, where oxygen is reserved in case its inflow through other channels decreases [3]. For this reason, data on hemoglobin content in the blood of Amphibia and its age, seasonal, and zonal peculiarities are an important characteristic of adaptive capacities of the species studied and well reflect the functional potential of each of them.

In 2010-2011, studies on hemoglobinometry of the blood of Amphibia were performed. The dependence of the hemoglobin content and species composition of Amphibia from different natural habitats was for the first time considered. Four species of anurans (Amphibia, Anura) that belong to the family Ranidae from the Ural upland area, including Pelophylax ridibundus Pallas, 1771; Rana temporaria Linnaeus, 1758; $R$. arvalis Nilsson., 1842; and $R$. amurensis Boulenger, 1886 (captured in populations that inhabit natural and urbanized areas), were considered. Urbanized areas were typified [4] according to the degree of their development by human and pollution level (I, multistorey building; II, low-rise building; III, woodland park; $\mathrm{K}$, out-of-town population). The hemoglobin con-

\footnotetext{
${ }^{a}$ Institute of Plant and Animal Ecology, Ural Branch, Russian Academy of Sciences, ul. Vos'mogo Marta 202, Yekaterinburg, 620144 Russia

${ }^{b}$ El'tsyn Ural Federal University, ul. Mira 19, Yekaterinburg, 620002 Russia
}

centration in blood was determined by means of an HG202 digital hemoglobinometer. In total, 266 yearlings and 94 adult individuals of moor frog, 71 yearlings and 49 adult individuals of lake frog, 56 yearlings and 110 adult individuals of grassy frog, and 80 adult individuals of Siberian frog were studied.

Significant interspecific differences $(F(3,108)=$ 4.9451, $p=0.00295$ ) were detected in adult animals. The level of hemoglobin increases in the order $P$. ridibundus $-R$. arvalis $-R$. temporaria $-R$. amurensis (Fig. 1). The results obtained to a large extent reflect the differences in lifestyle, as well as places and ways of wintering of the species studied.

The high hemoglobin content in grassy and Siberian frogs is due to the fact that the members of this genus are water-wintering forms of brown frogs that spend the period of hibernation at the bottom of ponds under the conditions of oxygen deficiency. It is interesting that the hemoglobin content is quite low in the water-wintering lake frog, which is associated with water during the entire lifecycle. This is explained by

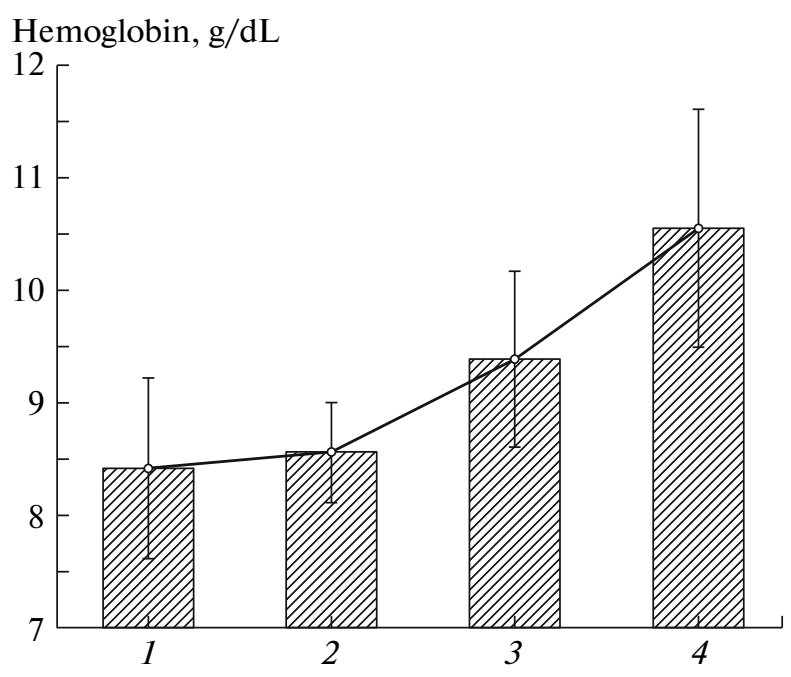

Fig. 1. Hemoglobin content in the blood of adult mature animals. $1, P$. ridibundus; $2, R$. arvalis; $3, R$. temporaria; 4, R. amurensis. 


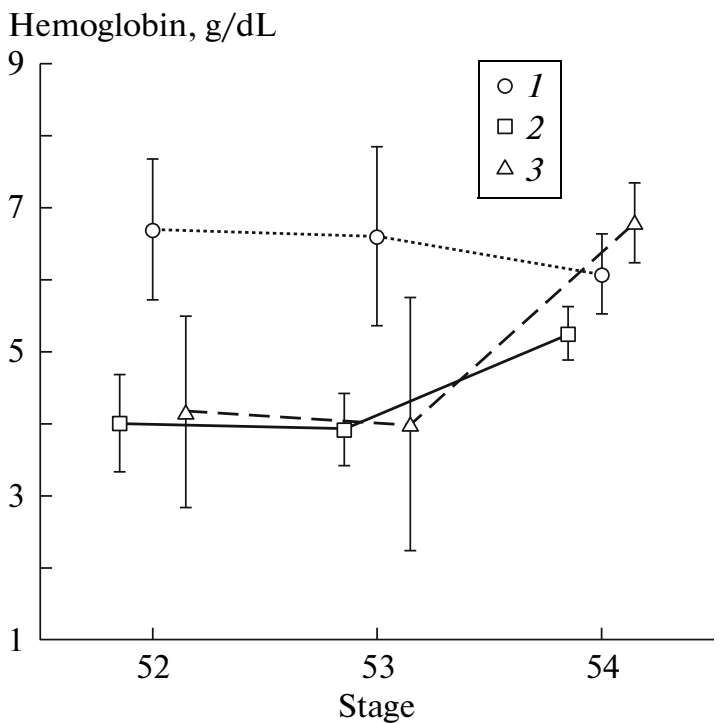

Fig. 2. Change in hemoglobin concentration in the period of metamorphosis completion. Here and in Figs. 3 and 4: $1, P$. ridibundus; $2, R$. arvalis; $3, R$. temporaria.

the fact that the affinity of the respiratory pigment to oxygen is considerably higher in water amphibians [5].

In addition, high hemoglobin concentrations in the blood are in this case a parameter that limits the possibility of the existence of the species under the conditions of anthropogenic eutrophication, chemical and thermal water basin pollution. High temperatures and the presence of hydrogen sulfide in the water of urban water basins (related to a high amount of organic matter) cause a decrease in the concentrations of dissolved oxygen and deprive grassy and Siberian frogs of suitable places for wintering. According to our data, the sensitivity to anthropogenic transformation

Table 1. Geographic differences in hemoglobin content (g/dL) in immature $R$. temporaria and mature $R$. amurensis

\begin{tabular}{c|c|c|c}
\hline Species & North Urals & Middle Urals & South Urals \\
\hline R. temporaria & $\begin{array}{c}4.4 \pm 0.28 \\
(n=28)\end{array}$ & $\begin{array}{c}6.7 \pm 0.27 \\
(n=29)\end{array}$ & No data \\
R. amurensis & No data & $\begin{array}{c}12.7 \pm 0.70 \\
(n=6)\end{array}$ & $\begin{array}{c}10.5 \pm 0.52 \\
(n=11)\end{array}$ \\
\hline
\end{tabular}

Table 2. Seasonal differences in hemoglobin content $(\mathrm{g} / \mathrm{dL})$ in $R$. amurensis and $R$. arvalis

\begin{tabular}{l|c|c|l}
\hline \multicolumn{1}{c|}{ Species } & July & August & $\begin{array}{l}\text { Significance of dif- } \\
\text { ferences }\end{array}$ \\
\hline $\begin{array}{l}\text { R. arvalis } \\
\text { (mature) }\end{array}$ & $\begin{array}{c}7.95 \pm 0.3 \\
(n=23)\end{array}$ & $\begin{array}{c}8.96 \pm 0.3 \\
(n=19)\end{array}$ & $\begin{array}{l}F(1.40)=5.4628 ; \\
p=0.025\end{array}$ \\
$\begin{array}{l}\text { R. amurensis } \\
\text { (mature) }\end{array}$ & $\begin{array}{c}9.9 \pm 0.5 \\
(n=7)\end{array}$ & $\begin{array}{c}11.6 \pm 0.6 \\
(n=4)\end{array}$ & $\begin{array}{l}F(1.9)=4.1782 ; \\
p=0.07 \text { (nonsignif- } \\
\text { icant) }\end{array}$ \\
$\begin{array}{l}\text { R. amurensis } \\
\text { (immature) }\end{array}$ & $\begin{array}{l}5.8 \pm 0.2 \\
(n=41)\end{array}$ & $\begin{array}{l}9.4 \pm 0.3 \\
(n=16)\end{array}$ & $\begin{array}{l}F(1.55)=84.655 ; \\
p=0.000001\end{array}$ \\
\hline
\end{tabular}

of the environment in the grassy and Siberian frogs is higher than in the lake frog. The high concentrations of hemoglobin in the blood in this case do not provide an advantage under the conditions of anthropogenic eutrophication, chemical and thermal water basin pollution. Thus, the level of hemoglobin in the blood is a marker of Amphibia sensitivity to anthropogenic transformation of the environment.

Significant changes $(F(4,271)=4.8306, p=$ 0.00089 ) in this indicator during the completion of metamorphosis (Fig. 2), as well as in the period from yearlings to mature animals, were found. The dynamics of changes during the completion of metamorphosis between stages 52 and 54 [6] is similar for brown frogs ( $R$. temporaria and $R$. arvalis), whose yearlings leave water medium after the completion of metamorphosis, which is expressed in the growth of hemoglobin content by the 54th stage. No significant changes in this parameter has been found in the $P$. ridibundus (which does not leave the water basin in this period and continues to lead water or near-water way of life); this may be due to specific cenogenetic adaptations in brown and green frogs.

Geographic differences in habitation of Amphibia (Table 1) consist in a significant $(F(1,55)=34.989$, $p=0.000001$ ) increase in the hemoglobin content in the blood of immature individuals of the grassy frog when moving from north (Chan'va River, North Urals, $59^{\circ} 25^{\prime} \mathrm{N}, 57^{\circ} 27^{\prime} \mathrm{N}$ ) to south (Vogulka River, Middle Urals, $57^{\circ} 05^{\prime} \mathrm{N}, 58^{\circ} 20^{\prime} \mathrm{E}$ ), as well as a considerable $(F(1,15)=6.0464, p=0.03)$ decrease in this parameter in Siberian frog when moving from the Middle Urals (Yalynka River, 58 $04.277^{\prime} \mathrm{N}, 63^{\circ} 40.991^{\prime}$ E) to

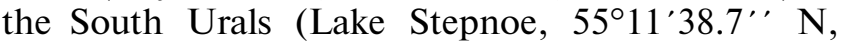
$67^{\circ} 28^{\prime} 22.7^{\prime \prime}$ E). It is possible that the increase in the hemoglobin content when moving from northern populations of grassy frog to Middle Ural populations is due to ecological differences in the habitats (even low hemoglobin concentrations ensure a sufficient oxygen saturation of the blood in northern populations).

The lower hemoglobin content in the populations of Siberian frog of the South Urals may be due to a high warming of habitats in the forest-steppe zone and geochemical specificity of water basins (the high nitrate $(4.95 \mathrm{mg} / \mathrm{L})$ and nitrite $(0.09 \mathrm{mg} / \mathrm{L})$ concentrations (which indicate eutrophy), as well as high mineralization $(650 \mathrm{mg} / \mathrm{L})$ and chloride content (135 mg/L at $\mathrm{pH} 7.4)$ ).

Seasonal changes in hemoglobin concentrations (growing from July to August) were found in moor and Siberian frogs (Table 2), which was probably due to seasonal physiological rearrangements (approaching of the time of wintering).

With urbanization, a decrease in the hemoglobin content was observed in yearlings (Fig. 3) of grassy, moor, and lake frogs $(F(4,245)=10.172, p=$ 


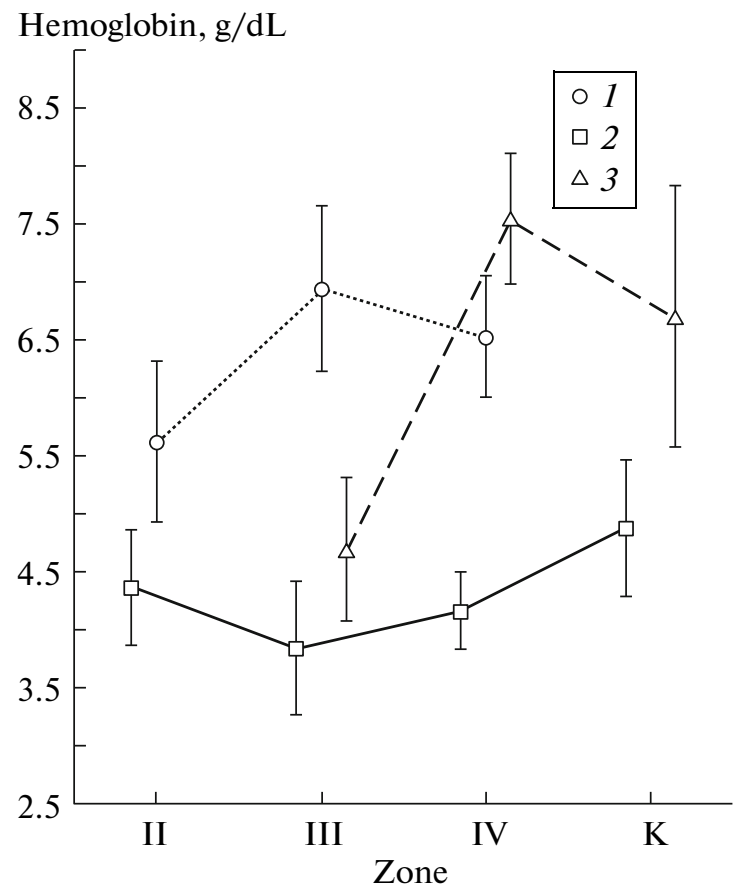

Fig. 3. Hemoglobin content in yearlings as related to urbanization.

0.00000 ), as well as in mature (Fig. 4) moor and grassy frogs $(F(3,68)=8.6755, p=0.00006)$.

A decrease in the hemoglobin concentration in the blood of animals that inhabit urbanized territories occurs under the conditions of eutrophication and pollutionaccompanied by hypooxygeny [7] (manifested as respiratory depression under the influence of pollutants [8]). It should be noted that the most considerable fall in hemoglobin content on residential areas was determined for the $R$. temporaria, which is the first out of the considered species to disappear from urbanized areas.

Thus, the first data on the hemoglobin content in the blood of four Amphibian species from the family Ranidae in the Urals were obtained. Differences associated with the latitudinal zones and accompanying climatic and geochemical peculiarities were detected. Seasonal differences in the hemoglobin concentrations caused by ontogenetic and seasonal physiological changes were found. A decrease in the hemoglobin content with urbanization was determined. It was demonstrated that high hemoglobin concentration in the blood was not the parameter that provided an advantage under the conditions of chemical and thermal pollution. In general, the data on the hemoglobin content in the blood of the members of the family studied reflect age, seasonal, and zonal dynamics characterizing the functional potential of each of the species.
Hemoglobin, g/dL

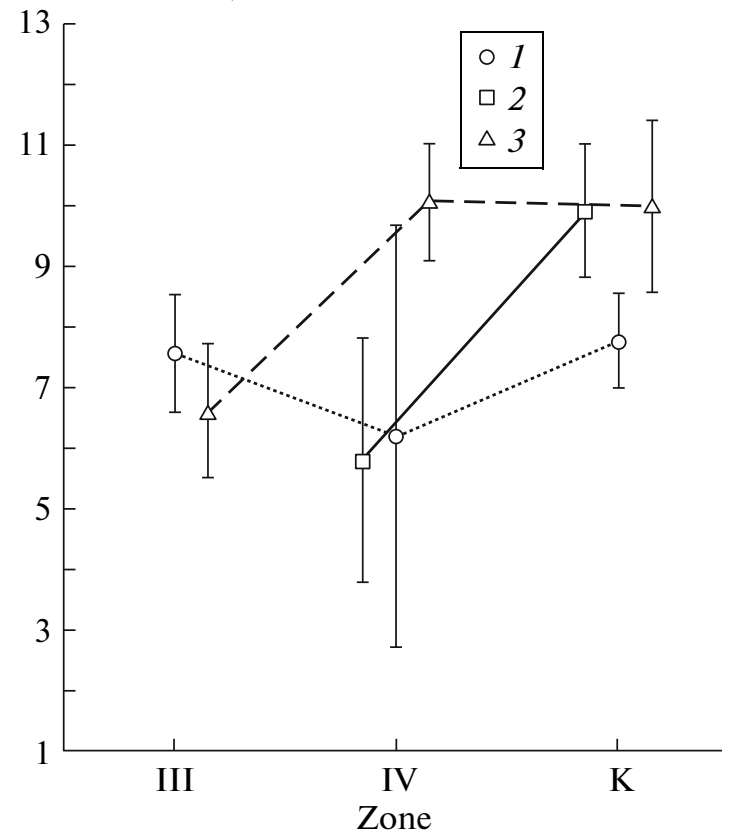

Fig. 4. Hemoglobin content in mature animals in the gradient of urbanization.

\section{ACKNOWLEDGMENTS}

This study was supported by the Russian Foundation for Basic Research-Ural, project no. 10-04-96084).

\section{REFERENCES}

1. Hillman, S.S., Withers, P.C., Drewes, R.C., and Hillyard, S.D., Ecological and Environmental Physiology of Amphibians, New York: Oxford Univ., 2009.

2. Ekologicheskaya fiziologiya zhivotnykh (Ecological Physiology of Animals), Slonim, A.D, Eds., Leningrad: Nauka, 1981.

3. Chugunov, Yu.D. and Kispoev, K.A., Dykhanie zemnovodnykh (prisposobleniya sistemy organov dykhaniya zemnovodnykh $k$ zhizni na granitse vody $i$ sushi) (Respiration of Amphibians: Adaptation of the Respiratory System of Amphibians to the Life at the Water-Land Boundary), Novosibirsk: Nauka, 1973.

4. Vershinin, V.L., in Informatsionnye materialy Instituta ekologii rastenii i zhivotnykh (Informational Materials of the Institute of Plant and Animal Ecology), Sverdlovsk, 1980, pp. 5-6.

5. Prosser, C.L. and Bishop, D.W., Comparative animal Physiology, Philadelphia: Saunders, 1950.

6. Dabagyan, N.V. and Sleptsova, L.A., Ob"ekty biologii razvitiya (Objects of Developmental Biology), Moscow, 1975.

7. Vershinin, V.L., Voprosy gerpetologii (Problems of Herpetology) (Proc. 4th Congress of Nikol'skii Herpetological Society), St. Petersburg: Russkaya Kollektsiya, pp. 56-65.

8. Testov, B.V., Effect of radioactive contamination on the populations of mouselike rodents, Extended Abstract of Doctoral (Biol.) Dissertation, Perm, 1993.

Translated by A. Barkhash 